\title{
The Economic Influence of Breastfeeding on the Health Cost of Newborns
}

(C) The Author(s) 2018

Article reuse guidelines: sagepub.com/journals-permissions DOI: I0.1 I77/08903344|88|2026 journals.sagepub.com/home/jhl

(\$SAGE

\author{
Esmeralda Santacruz-Salas, MSc, PhD', \\ Isaac Aranda-Reneo, $\mathbf{M S c} \mathbf{P h D}^{2}$ (D), \\ Álvaro Hidalgo-Vega, $\mathbf{M S c}, \mathbf{P h D}^{3}$, \\ José M. Blanco-Rodriguez, $\mathrm{MSc}, \mathrm{PhD}^{4}$, \\ and Antonio Segura-Fragoso, MD, PhD'
}

\begin{abstract}
Background: Breastfeeding provides health benefits for women and newborns. However, few studies have explored how these health benefits translate into economic savings.

Research aim: This study aimed to estimate the healthcare costs savings generated by exclusive breastfeeding for healthy newborns.

Methods: We designed a longitudinal two-group observational study that included healthy women and newborns $(N=$ 236) in Toledo, Spain. Over the first 6-months of the infants' lives, we reviewed their clinical histories to determine their consumption of healthcare resources and the type of nutrition provided. The sample was categorized into two groups: exclusive breastfeeding $(n=46)$ and non-exclusive breastfeeding for 6 months $(n=190)$. Two-part regression models were applied to determine whether there were differences in healthcare costs between the groups.

Results: The average age of the women was 32 (SD: 5.3). The average birth weight of the newborns was $3.3 \mathrm{~kg}$. (SD: 0.38 ). At 6 months, 19.5\% $(n=46)$ of the women breastfed exclusively, $28.4 \%(n=67)$ combined breastfeeding with formula, and $45.8 \%(n=108)$ used formula only. Healthcare costs during follow-up reached $€ 785.58$ (44\% for specialized care, $42 \%$ for primary care, $9.8 \%$ for medical emergencies, $3 \%$ for medications and approximately $1 \%$ for medical tests). The statistical analysis estimated a lower healthcare cost of between $€ 454.40$ and $€ 503.50$ for exclusively breastfed newborns.

Conclusion: Breastfeeding generated savings in healthcare costs; therefore, it could be a cost-efficient option compared with alternatives. Researchers who evaluate the efficiency of strategies that promote breastfeeding can contribute to the sustainability of health services.
\end{abstract}

\section{Keywords}

Breastfeeding, breastfeeding benefits, cost benefit analysis, exclusive breastfeeding, health services research.

\section{Background}

Breastfeeding is considered the best way to nourish and promote the proper development of a newborn by both the World Health Organization (WHO; 2009) and the United Nations Children's Fund (UNICEF; 2011), especially when breastfeeding is the exclusive source of nutrition. It has been established that breastfeeding provides multidimensional health benefits which favor the immunological development of the newborn (Bridgman et al., 2016; Palmeira \& Carneiro-Sampaio, 2016; Petersen, 2017). In the short term, breastfeeding contributes to reduced morbidity and infant mortality and, in the long term, it is associated with better intellectual and motor development and the prevention of chronic diseases (Amitay \& KeinanBoker, 2015).
Breastfeeding provides many other benefits that extend to the rest of society. These benefits are described in recently

\footnotetext{
'Faculty of Occupational Therapy, Speech Therapy and Nursing,

University of Castilla-La Mancha, Talavera de la Reina. Toledo, Spain

${ }^{2}$ Faculty of Social Sciences, University of Castilla-La Mancha, Talavera de la Reina. Toledo, Spain

${ }^{3}$ Faculty of Law and Social Sciences, University of Castilla-La Mancha,

Toledo, Spain

${ }^{4}$ Faculty of Nursing, Physiotherapy and Podiatry, Complutense University of Madrid, Madrid, Spain
}

Date submitted: January 29, 2018; Date accepted: October I8, 2018.

Corresponding Author:

Isaac Aranda-Reneo, Faculty of Social Sciences, University of Castilla-La Mancha, Avda. Real Fábrica de Seda s/n, 45600, Talavera de la Reina, Spain. Email: Isaac.aranda@uclm.es 


\section{Acknowledgments}

Isaac Aranda-Reneo and Álvaro Hidalgo-Vega would like to acknowledge the support received from the research project ECON2013-48217-C2-2-R "Economic, health and social impact of diseases and health problems: information and tools for evaluating public policies" founded by the Spanish government. All authors would like to acknowledge the study participants for their kind participation.

\section{Declaration of Conflicting Interests}

The authors declared no potential conflicts of interest with respect to the research, authorship, and/or publication of this article.

\section{Funding}

The authors disclosed receipt of financial support for the publication of this article from the research project ECON2013-48217-C22-R "Economic, health and social impact of diseases and health problems: information and tools for evaluating public policies" funded by the Spanish government.

\section{ORCID iD}

Isaac Aranda-Reneo iD https://orcid.org/0000-0002-7311-2615

\section{References}

Amitay, E. L., \& Keinan-Boker, L. (2015). Breastfeeding and childhood leukemia incidence: A meta-analysis and systematic review. JAMA Pediatrics, 169(6), e151025. doi:10.1001/jamapediatrics.2015.1025

Balogun, O. O., Dagvadorj, A., Anigo, K. M, Ota, E., \& Sasaki, S. (2015). Factors influencing breastfeeding exclusivity during the first 6 months of life in developing countries: A quantitative and qualitative systematic review. Maternal \& Child Nutrition, 11(4), 433-451.

Bartick, M. (2011). Breastfeeding and the U.S. economy. Breastfeeding Medicine, 6, 313-318. doi:10.1089/bfm.2011.0057

Bartick, M. C., Stuebe, A. M., Schwarz, E. B., Luongo, C., Reinhold, A. G., \& Foster, E. M. (2013). Cost analysis of maternal disease associated with suboptimal breastfeeding. Obstetrics and Gynecology, 122(1), 111-119. doi:10.1097/ AOG.0b013e318297a047

Bartick, M., \& Reinhold, A. (2010). The burden of suboptimal breastfeeding in the United States: A pediatric cost analysis. Pediatrics, 125(5), e1048-1056. doi:10.1542/peds.2009-1616

Bobrow, K. L., Quigley, M. A., Green, J., Reeves, G. K., \& Beral, V. (2013). Persistent effects of women's parity and breastfeeding patterns on their body mass index: Results from the Million Women Study. International Journal of Obesity, 37(5), 712-717.

Branch-Elliman, W., Lee, G. M., Golen, T. H., Gold, H. S., Baldini, L. M., \& Wright, S. B. (2013). Health and economic burden of postpartum Staphylococcus aureus breast abscess. PLoS One, 8(9), e73155. doi:10.1371/journal.pone.0073155

Bridgman, S. L., Konya, T., Azad, M. B., Sears, M. R., Becker, A. B., Turvey, S. E., . . Kozyrskyj, A. L. (2016). Infant gut immunity: A preliminary study of IgA associations with breastfeeding. Journal of Developmental Origins of Health and Disease, 7(1), 68-72. doi:10.1017/s2040174415007862
Brown, A. (2017). Breastfeeding as a public health responsibility: A review of the evidence. Journal of Human Nutrition and Dietetics. doi:10.1111/jhn.12496

Chen, L. W., Wilson, F. A., Gregg, A., Gupta, N., Bekmuratova, S., \& Palm, D. (2017). Measuring the cost and value of quality improvement initiatives for local health departments. Journal of Public Health Management and Practice. doi:10.1097/ phh.0000000000000552

Colaizy, T. T., Bartick, M. C., Jegier, B. J., Green, B. D., Reinhold, A. G., Schaefer, A. J., . . Stuebe, A. M. (2016). Impact of optimized breastfeeding on the costs of necrotizing enterocolitis in extremely low birthweight infants. The Journal of Pediatrics, 175, 100-105.e102. doi:10.1016/j.jpeds.2016.03.040

Colchero, M. A., Contreras-Loya, D., Lopez-Gatell, H., \& Gonzalez de Cosio, T. (2015). The costs of inadequate breastfeeding of infants in Mexico. The American Journal of Clinical Nutrition, 101(3), 579-586. doi:10.3945/ajcn.114.092775

Dritsakou, K., Liosis, G., Valsami, G., Polychronopoulos, E., Souliotis, K., \& Skouroliakou, M. (2016). Mother's breast milk supplemented with donor milk reduces hospital and health service usage costs in low-birthweight infants. Midwifery, 40, 109-113. doi:10.1016/j.midw.2016.06.015

Drummond, M., Schulpher, M., Claxton, K., Stoddart, G., \& Torrance, G. (2015). Methods for the economic evaluation of health care programmes (4th ed.). Oxford University Press.

Economou, A., Nikolaou, A., \& Theodossiou, I. (2008). Socioeconomic status and health-care utilization: A study of the effects of low income, unemployment and hours of work on the demand for health care in the European Union. Journal of Health Services Management Research, 21, 40-59.

Elwood, M. (2007). Critical appraisal of epidemiological studies and clinical trials (3rd ed.). Oxford: Oxford University Press.

Ganapathy, V., Hay, J. W., \& Kim, J. H. (2012). Costs of necrotizing enterocolitis and cost-effectiveness of exclusively human milk-based products in feeding extremely premature infants. Breastfeeding Medicine, 7(1), 29-37. doi:10.1089/ bfm.2011.0002

Harding, J., \& Hilbe, J. (2012). Generalized linear models and extensions (3rd ed.). Stata Press.

Husereau, D., Drummond, M., Petrou, S., Carswell, C., Moher, D., \& and...Greenberg, D. (2013). Ispor Health Economic Evaluation Publication Guidelines-CHEERS Good Reporting Practices Task Force. Consolidated health economic evaluation reporting standards (CHEERS)-Explanation and elaboration: A report of the ISPOR Health Economic Evaluation Publication Guidelines Good Reporting Practices Task Force. Value in Health, 16(2), 231-250. doi:10.1016/j.jval.2013.02.002

Johnson, T. J., Patel, A. L., Bigger, H. R., Engstrom, J. L., \& Meier, P. P. (2015). Cost savings of human milk as a strategy to reduce the incidence of necrotizing enterocolitis in very low birth weight infants. Neonatology, 107(4), 271-276. doi:10.1159/000370058

Lopez-Bastida, J., Oliva, J., Antonanzas, F., Garcia-Altes, A., Gisbert, R., Mar, J., \& Puig-Junoy, J. (2010). Spanish recommendations on economic evaluation of health technologies. The European Journal of Health Economics, 11(5), 513-520. doi:10.1007/s10198-010-0244-4

Ma, P., Brewer-Asling, M., \& Magnus, J. H. (2013). A case study on the economic impact of optimal breastfeeding. Maternal 